\title{
PENINGKATAN KAPABILITAS TEKNOLOGI DALAM MENGHADAPI ERA DISRUPSI PADA GENERASI MILENIAL MELALUI WEBINAR
}

\author{
Chandra Fitra Arifianto ${ }^{1 *}$, Anom Susilo ${ }^{2}$, Mutawali $^{3}$, Rahadyan Tajuddien ${ }^{4}$, Faisal Romdonih ${ }^{5}$ \\ 1,2,3,4,5 Fakultas Ekonomi, Universitas Pamulang \\ *E-mail: dosen01177@unpam.ac.id
}

\begin{abstract}
ABSTRAK
Pengabdian kepada masyarakat ini bertujuan untuk memberikan paradigma perlunya meningkatkan kapabilitas penggunaan teknologi terutama ponsel pintar pada generasi milenial. Ternyata banyak konsumen yang membeli kebutuhannya secara daring dan itu merupakan kesempatan yang dapat direbut. Permasalahan yang dihadapi oleh para generasi milenial ialah pemanfaatan ponsel pintar yang tidak maksimal karena kurangnya minat dan tidak menariknya wirausaha melalui daring. Melalui metode pelatihan berupa pemberian materi secara daring dengan aplikasi zoom atau biasa disebut webinar, peserta dapat bertanya secara langsung tanpa perlu berkumpul. Pada akhir kegiatan dilakukan dengan sesi tanya jawab sebagai bentuk evaluasinya. Hasil setelah mengikuti pelatihan, paradigma mereka terbuka untuk memunculkan minat mereka untuk memulai usaha secara daring hanya dengan memanfaatkan ponsel pintar mereka.
\end{abstract}

Kata kunci: Generasi milenial; ponsel pintar; kapabilitas teknologi; webinar

\section{TECHNOLOGICAL CAPABILITY IMPROVEMENT ON FACING THE ERA OF DISRUPTION IN THE MILLENIAL GENERATION THROUGH WEBINAR}

\begin{abstract}
This community service aims to provide a paradigm for the need to increase the capability of using technology, especially smart phones for the millennial generation. It turns out that many consumers buy their needs online and this is an opportunity that can be seized. The problem faced by the millennial generation is the inadequate use of smart phones due to a lack of interest and the lack of interest in online entrepreneurs. Through a training method in the form of providing material online with a zoom application or commonly called a webinar, participants can ask questions directly without needing to gather. At the end, the activity was carried out with a question and answer session as a form of evaluation. The result after participating in the training, their paradigm is open to arouse their interest to start an online business just by using their smartphone.
\end{abstract}

Keywords: Millenial generation; smartphones; technological capability; webinar

\section{PENDAHULUAN}

Semenjak era VUCA (Volatility, Uncertainty, Complexity, and Ambiguity) yang diartikan sebagai suatu hal yang mudah berubah dan meledak, tidak pasti, kompleks, dan adanya ketidakjelasan di tahun 90an, terjadi pergeseran perilaku sosial terhadap para generasi muda. Pergeseran ini diikuti pula dengan perubahan gaya hidup yang secara bersamaan perkembangan teknologi semakin marak pula. Generasi sekarang yang lebih dikenal sebagai generasi milenial, sangatlah tidak bisa dijauhkan dari teknologi. Terlebih lagi asupan teknologi tersebut menyatu ke dalam sebuah gawai. Yang paling banyak digunakan ialah ponsel pintar (smartphone).

Gaya hidup yang tidak tepat mungkin saja terjadi karena perilaku sosial yang kurang tepat dan bijak dalam memanfaatkan sosial media (Apsari dkk., 2018). Hal tersebut selalu dihadapkan dengan kondisi dimana mereka harus selalu berhati-hati di jaman keterbukaan saat ini. Terlebih lagi Haryanto (2020) mendata bahwa mobile phone (96\%) dan smartphone (94\%) menjadi pilihan utama pengguna internet antara rentang umur 16-64 tahun. Jadi tidak dapat dinafikkan lagi bahwa kebutuhan gawai 
BAKTI BANUA : Jurnal Pengabdian Kepada Masyarakat

Volume 1 No. 2 November 2020

e-ISSN : 2722-3736

p-ISSN : 2722-7529

https://ejurnal.stimi-bjm.ac.id/index.php/BBJM/

tersebut telah menjadi kebutuhan dalam keseharian manusia di Indonesia. Selanjutnya $64 \%$ penduduk Indonesia merupakan pengguna internet aktif. Belum lagi media sosial yang paling digandrungi ialah Youtube, Whatsapp, Facebook, dan selanjutnya Instragram. Semakin komplitlah keaktifan dan kerigidan ke dalam dunia maya.

Era disrupsi menuntut adanya evolusi dalam sistem pendidikan agar menghasilkan generasi yang unggul. Disrupsi sendiri merupakan perubahan yang merupakan keniscayaan. Perubahan itu sendiri berlangsung di semua sektor dan segala aspek kehidupan masyarakat. Salah satu yang pesat dalam perubahan ialah teknologi. Disrupsi saat ini dipicu oleh revolusi industri 4.0. Tanda-tandanya ialah adanya perpaduan teknologi yang berakibat kurangnya sekat-sekat antara dunia fisik, digital dan biologi (Syafarudin, 2020). Keunggulan yang ada pada generasi tersebut dalam hal produksi, inovasi, kreasi, serta dalam hal jiwa kewirausahaan. Sehingga era disrupsi menuntut generasi milenial untuk bisa memberikan berbagai solusi dari berbagai permasalahan yang ada. Apabila generasi milenial tidak mampu menghadirkan solusi maka akan tergerus dan semakin terpuruk serta akan kesulitan membangun eksistensinya. Padahal generasi milenial itu sendiri merupakan generasi yang produktif, kreatif, inovatif dan berjiwa kewirausahaan.

Ada kekhasan dari generasi milenial ini sendiri adalah ditandai dengan keakraban dan peningkatan penggunaan komunikasi, media dan teknologi digital. Mereka terlahir dimana dunia modern dan teknologi canggih, seperti gawai, diperkenalkan ke publik. Inilah mengapa generasi milenial sangat melek teknologi (Saputro, 2019). Generasi milenial juga memiliki sifat yang lebih toleran terhadap sesamanya. Karena arus globalisasi yang masif, anak muda tersebut dapat berinteraksi dengan manusia manapun di belahan dunia ini.

Namun apakah para generasi milenial mengetahui atau bahkan mampu mengoperasikan gawainya untuk dijadikan sarana untuk dapat mengais rejeki. Telah banyak penelitian yang menunjukkan bahwa metode daring sangat telah banyak dilakukan, seperti Situmeang (2018) yang menunjukkan bahwa bisnis daring memberikan pekerjaan dan Izzati (2015) juga menyimpulkan bahwa penggunaan gawai untuk promosi malah lebih nyaman. Oleh karenanya dapat dilihat adanya peluang dalam pemanfaatan gawai untuk berwirausaha pada generasi milenial. Untuk itulah perlunya penguasaan kapasitas teknologi.

Teknologi adalah keseluruhan sarana untuk menyediakan barang-barang yang diperlukan bagi kelangsungan dan kenyaman hidup manusia. Teknologi itu juga telah banyak mempengaruhi masyarakat dan sekelilingnya dengan segala caranya. Di berbagai kasus di belahan dunia, banyak pertumbuhan ekonomi secara signifikan. Jadi dapat disimpulkan bahwa teknologi banyak yang memberikan perubahan positif. Termasuk ketika di era generasi milenial, yang tidak bisa dilepaskan dari teknologi.

Pemanfaatan gawai sendiri banyak digunakan hanya untuk mencari informasi, berselancar dan bersosialisasi melalui media sosial. Hanya sedikit dari generasi milenial yang tertarik untuk melakukan usaha dengan memanfaatkan gawai tersebut. Oleh karenanya, perlu untuk memperkuat keyakinan pada generasi milenial untuk dapat memanfaatkan gawai tersebut untuk menjalankan usaha. Terlebih lagi masih banyak generasi milenial yang belum tertarik untuk berwirausaha dengan memanfaatkan teknologi yang ada di dalam gawai pintarnya

Bahkan di era saat inipun untuk menjadi pengusaha lebih mudah dengan bantuan teknologi. Namun permasalahan lainnya ialah gaya hidup generasi milenial acap kali konsumtif (Taufiq dkk., 2018). Berarti perlu bagi generasi milenial untuk memanfaatkan teknologi dengan sebaik-baiknya. Teknologi sangat berperan dalam memajukan bisnis mereka. Untuk itu, perlu peningkatan kapabilitas teknologi pada diri mereka. Kajian LIPI (2014) pun menunjukkan bahwa sektor yang perlu dibenahi adalah kapasitas inovasi, kapasitas teknologi dan kemampuan industri yang rendah. Sehingga kapasitas teknologi di generasi milenial perlu untuk ditingkatkan mengingat ini merupakan hal utama. Untuk itulah PKM ini dirasa cocok untuk mengisi kebutuhan tersebut. 
BAKTI BANUA : Jurnal Pengabdian Kepada Masyarakat

Volume 1 No. 2 November 2020

e-ISSN : 2722-3736

p-ISSN : 2722-7529

https://ejurnal.stimi-bjm.ac.id/index.php/BBJM/

\section{METODE}

Melihat betapa maraknya penggunaan ponsel pintar di kalangan masyarakat, terlebih lagi generasi milenial, tentulah dapat dilihat dari dua sisi. Sisi positif, mereka bisa menggali berbagai banyak informasi yang tak terhingga. Sedangkan sisi negatifnya, tak terelakkan lagi ialah ponsel pintar hanya dipakai untuk memperbarui status, berfoto ria, hingga membuat hal yang infaedah. Inilah yang acap kali dianggap tidak bisa memaksimalkan teknologi uang ada di ponsel pintarnya tersebut untuk berbuat hal positif. Untuk itulah kerangka pemecahan permasalahannya tergambarkan dalam gambar berikut:

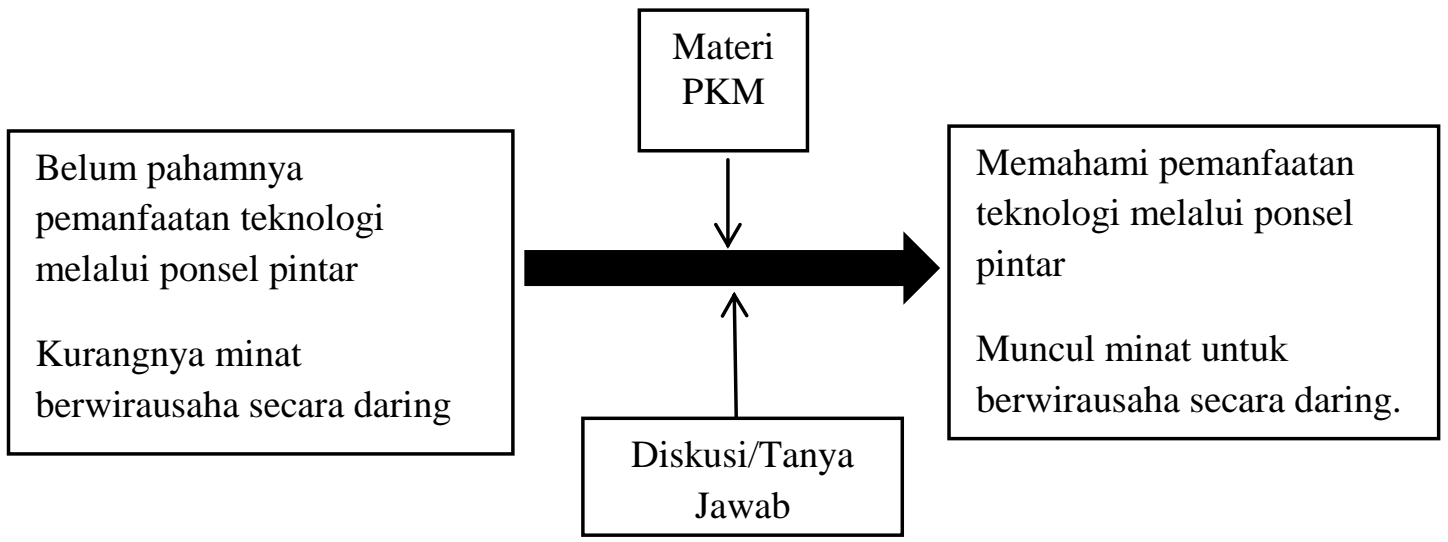

Gambar 1. Kerangka Pemecahan Masalah

Mengingat kondisi pandemi Covid-19 dan tidak diperkenankan oleh Pemerintah untuk melakukan pelatihan secara langsung, maka pelatihan ini dilakukan secara daring dengan aplikasi zoom. Ini seringkali dikenal dengan nama webinar. Penggunaan aplikasi ini bisa dijadikan alternatif sebagai media pembelajaran media secara daring (Brahma, 2020). Sehingga seluruh rangkaian kegiatan dapat disampaikan dengan baik dan pada akhir kegiatan dilakukan sesi tanya jawab sebagai bentuk evaluasinya. Jadi gambaran metode kegiatannya berupa pemberian materi oleh tim dosen Universitas Pamulang.

Kegiatan pemecahan masalah dilakukan dengan mengadakan pelatihan secara daring (webinar) dengan aplikasi zoom. Metode webinar ini dipilih karena sebagai solusi yang tepat untuk dapat meningkatkan kompetensi peserta secara daring (Harumiaty, 2016). Kegiatan penyuluhan ini berupa pemberian materi oleh para dosen kepada peserta dengan memberikan pengetahuan dan gambaran riil di lapangan terkait pemanfaatan teknologi dasar yang ada di ponsel pintar, seperti aplikasi, kamera, browser, dan gambar/galeri. Hal tersebut perlu diingatkan kembali untuk memaksimalkan operasionalisasinya. Lalu pemanfaatan aplikasi yang dapat digunakan untuk berniaga. Beberapa contoh seperti: Facebook ads (Dehghani \& Tumer, 2015), Whatsapp Business (Firoz, 2020), Tokopedia (Mohansyah \& Parani, 2018), Shopee (Fauziah, 2020), Bukalapak (Sujanto, 2018) dan sebagainya.

Berikutnya dilanjutkan dengan pelatihan untuk membuka paradigma dan memunculkan minat untuk berwiraswasta. Pemateri memberikan contoh salah satu dosen yang berhasil membangun bisnis dengan memanfaatkan teknologi, yaitu secara daring. Dia mampu menjual barang hingga ke Kalimantan dan Papua, yang notabene jauh dari lokasi usahanya. Ditunjukkan pula bahwa semenjak kemunculan toko jual beli daring, konsumen lebih memilih untuk membeli barang melalui daring. Inilah yang disebut kesempatan dan target pasar yang jelas dan banyak. Sedangkan sasaran kegiatan PKM ini adalah seluruh generasi milenial (berusia 16-25 tahun) yang bersedia mengikuti webinar kita. Iklan webinar ini ditayangkan selama sebulan (20 Maret - 21 April 2020) dan Pengabdian Kepada 
BAKTI BANUA : Jurnal Pengabdian Kepada Masyarakat

Volume 1 No. 2 November 2020

e-ISSN : 2722-3736

p-ISSN : 2722-7529

https://ejurnal.stimi-bjm.ac.id/index.php/BBJM/

Masyarakat ini berlangsung secara daring di tanggal 13 Juni 2020 dengan dioperasikan oleh Kaweroo Institute di J1. Akses UI, Kelapa Dua, Kota Depok, Jawa Barat.

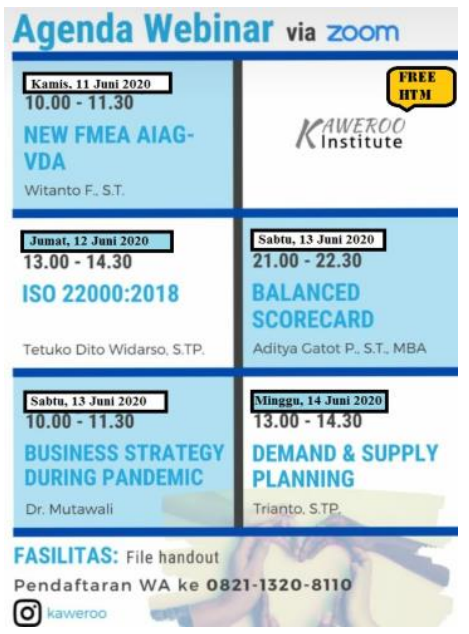

Gambar 2. Iklan kegiatan webinar

\section{HASIL DAN PEMBAHASAN \\ Isi Hasil dan Pembahasan}

Pengabdian Kepada Masyarakat (PKM) yang dilakukan oleh dosen-dosen manajemen Universitas Pamulang telah berjalan dengan lancar. Dikarenakan adanya pandemi Covid-19, PKM ini terpaksa dilakukan dengan melalui aplikasi oom. Inilah yang lebih dikenal dengan istilah webinar. Meskipun pelatihan diberikan secara daring, tidak mengurangi antusias para peserta yang merupakan generasi milenial. Kegiatan ini dimoderasi dan dimanajemeni oleh Bapak Anom Susilo, S.T., M.B.A.

Dosen-dosen memberikan penjelasan tentang bagaimana pemanfaatan teknologi untuk dapat dijadikan media untuk berwirausaha. Penggunaan ponsel pintar untuk media promosi dianggap efektif mengingat hampir semua orang memiliki ponsel pintar tersebut. Belum lagi ternyata banyak konsumen yang lebih memilih untuk berbelanja menggunakan media daring, terlebih ponsel pintar.

Salah satu pemateri Bapak Dr. Mutawali, S.E.I., M.M. membagikan tips dan triknya dalam mengembangkan usahanya dengan memanfaatkan teknologi, yaitu ponsel pintar. Menurutnya di era teknologi seperti ini, sangatlah mudah dan menjanjikan berbisnis hanya dengan menggunakan gawai. Cukuplah bagi para pengusaha untuk memasarkan produknya di berbagai pilihan situs jual beli seperti tokopedia, bukalapak, shopee, facebook ad, whatsapp business, dan semcamnya. Saat ini sangatlah tinggi propabilitas penjualan produk melalui daring. Yang diperlukan hanyalah membuat akun, menggunggah gambar dan tunggulah pembeli datang.

Berikutnya materi yang dibawakan oleh Bapak Chandra Fitra Arifianto, S.Psi., M.M., lebih menitikberatkan ke paradigma berpikir para generasi milenial. Sangatlah tidak kekinian apabila hanya mereka berperan sebagai pembeli tanpa berperan juga menjadi penjual. Cara berpikir inilah yang perlu digaungkan kepada generasi milenial saat ini. Berbagai kemudahan yang ada, hendaklah dapat dimanfaatkan untuk menggali peluang berbisnis. Paling mudah ialah dengan menawarkan ke temanteman baik dengan whatsapp group atau membuat blasting pesan. Namun pada dasarnya hal terpenting adalah ketertarikan dan kemauan. Untuk itulah pelatihan ini dilakukan.

Bentuk antusiasme peserta ialah ketika bermunculan banyak pertanyaan dengan memanfaatkan media chat yang ada di aplikasi zoom tersebut. Salah satu pertanyaan yang menarik ialah "Bagaimana untuk memulai bisnis ketika kita tidak memiliki modal?". Salah satu dosen, Bapak Rahadyan Tajuddien, S.E., M.M. yang memiliki kepakaran dalam pemasaran memberikan penjelasan dengan 
BAKTI BANUA : Jurnal Pengabdian Kepada Masyarakat

Volume 1 No. 2 November 2020

e-ISSN : 2722-3736

p-ISSN : 2722-7529

https://ejurnal.stimi-bjm.ac.id/index.php/BBJM/

sederhana agar mudah dipahami. Menurut beliau "Bukankah handphone dan pikiran kalian adalah modal? Karena hal itulah yang terpenting dan mutlak harus dimiliki dan dikuasai". Maksudnya di sini ialah pikiranlah yang menentukan barang apa yang bisa dijual. Apabila ternyata tidak punya barang, bukankah kita bisa menjadi reseller dengan menjualkan barang milik orang lain. Sedangkan handphone diperlukan untuk mempromosikan produk tersebut. Dimulai dengan mengambil foto, mengunggah hingga memposting di akun jual beli daring yang diinginkan.

Bapak Faisol Romdonih, S.Sos.i., M.Si., juga mengingatkan kembali kepada para generasi milenial bahwa $i k h t i a r$ atau usahalah yang terpenting. Seberapa beratnya jalan yang akan dilalui ketika berbisnis, percayalah bahwa hasil yang setimpal akan diterimanya. Itulah mengapa banyak pengusaha sukses yang harus jatuh bangun sebelum mereka meraih kesuksesannya setelah bertahun-tahun lamanya. Terlebih mental para milenial yang cenderung ingin menggapai kesuskesan secara singkat tentu saja akan menjadi hambatan tersendiri. Oleh karenanya, kepercayaan terhadap apa yang kita lakukan akan menelurkan hasil yang niscaya tidak akan mengecewakan. Jadi semuanya itu perlu proses dan pengorbanan.
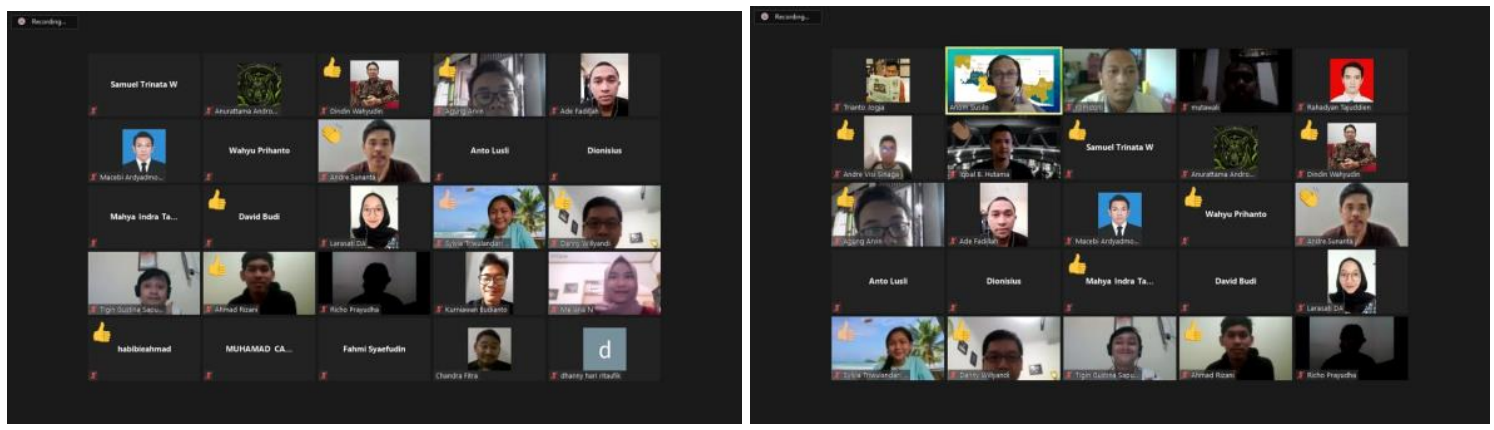

Gambar 2. Tampilan kegiatan webinar

\section{SIMPULAN}

Secara singkat kegiatan Pengabdian Kepada Masyarakat (PKM) yang dilakukan oleh dosen-dosen manajemen Universitas Pamulang telah berlangsung dengan lancar. Materi-materi yang disampaikan dapat diterima dengan mudah oleh para peserta yang merupakan generasi milenial. Bentuk pertanyaan yang ditanyakan merupakan indikasi sinyal positif atas kegiatan PKM berbentuk webinar ini.

Namun ada beberapa kekurangan yang perlu diperbaiki seperti keterbatasan sarana dan media di dalam menyampaikan materi. Sehingga kiranya apabila diperbolehkannya kegiatan pelatihan secara tatap muka seperti sedia kala, maka akan dilakukan praktik aplikasi menggunakan media ponsel pintar. Untuk itulah itu dapat dimasukkan sebagai perencanaan ke depan.

\section{UCAPAN TERIMAKASIH (jika ada)}

Teriring ucapan terima kasih kepada LPPM Universitas Pamulang untuk pemberian dana PKM ini.

\section{DAFTAR PUSTAKA}

Apsari, F., Darmawan, M., dan Prasetyo, E. 2018. Pemanfaatan Teknologi bagi Generasi Millenial: Konseling Berbasis Teks Menggunakan Riliv-Aplikasi Android. Jurnal Experientia. 6 (1) 45-49.

Brahma, I. 2020. Penggunaan Zoom sebagai Pembelajaran Berbasis Online dalam Mata Kuliah Sosiologi dan Antropologi pada Mahasiswa PPKN di STKIP Kusumanegara Jakarta. Jurnal Ilmu Pendidikan Nonformal Aksara. 6 (2) 97-102. 
BAKTI BANUA : Jurnal Pengabdian Kepada Masyarakat

Volume 1 No. 2 November 2020

e-ISSN : 2722-3736

p-ISSN : 2722-7529

https://ejurnal.stimi-bjm.ac.id/index.php/BBJM/

Dehghani, M. dan Tumer, M. 2015. A Research on Effectiveness of Facebook Advertising on Enhancing Purchase Intention of Consumers. Computers in Human Behavior. 49 597-600.

Fauziah. 2020. Strategi Komunikasi Bisnis Online Shop "Shoppe" dalam Meningkatkan Penjualan. Jurnal Abiwara. 1 (2) 45-53.

Firoz, N. 2020. Learning from WhatsApp's Business Model: The World of Messaging Apps. The Journal of American Academy of Business. 25 (2) 10-17.

Harumiaty, N. 2016. Belajar Mandiri menggunakan Webinar untuk meningkatkan Kompetensi Pustakawan di Indonesia. Prosiding Konferensi Call for Paper \& Musda III FPPTI Jawa Timur 21-23 September 2016 di Sumenep.

Haryanto, A. 2020. Riset: ada 175,2 juta pengguna internet di Indonesia. (https://inet.detik.com/cyberlife/d-4907674/riset-ada-1752-juta-pengguna-internet-di-indonesia, diakses 31 Juli 2020).

Izzati, N. 2015. Motif Penggunaan Gadget Sebagai Sarana Promosi Bisnis Online di Kalangan Mahasiswa UIN Sunan Kalijaga. Jurnal Komunikasi ASPIKOM. 2 (5) 374-380.

LIPI. 2014. Kapasitas Inovasi dan Kapasitas Teknologi Industri Indonesia masih rendah. (http://lipi.go.id/id/berita 2Fsingle 2Fkapasitas-inovasi-dan-kapabilitas-teknologi-industriindonesia-masih-rendah-2F13650, diakses 31 Juli 2020).

Mohansyah dan Parani. 2018. Digital Online dan Trust dalam Hubungan Antara Tokopedia dengan Pengguna Layanan. Jurnal Lontar. 6 (1) 58-68.

Saputro, F. 2019. Peran dan Tantangan Pemuda "di Era Generasi Milenial". (https://pustakabergerak.id/artikel/peran-dan -pemuda-di-era-generasi-millenial, diakses $31 \mathrm{Juli}$ 2020).

Situmeang, R. 2018. Dampak Bisnis Online dan Lapangan Pekerjaan terhadap Peningkatan Pendapatan Masyarakat (Studi Kasus Jasa Bisnis Online Transportasi Grab di Kota Medan). Asian Journal of Innovation and Entrepreneurship. 3 (3) 319-335.

Sujanto, R. 2018. Strategi Komunikasi Sosial Komunitas Pelapak Bukalapak. Channel. 6 (1) 106-119.

Syafarudin. 2020. Disrupsi Pemerintah dan Politik Era 4.0. (https://www.unila.ac.id/disrupsipemerintahan-dan-politik-era-4-0/, diakses 31 Juli 2020).

Taufiq, A., Mandasari, A., dan Romdani, A. 2018. Analisis Faktor-faktor Pembentuk Konsumsi Status pada Generasi Millenial. Jurnal Ekonomi Manajemen. 4 (2) 143-149. 